\title{
U-City Service Classification Standard \& Cost Sharing Plan through the Case Studies of U-City Construction
}

\author{
Jeong-Ran Yun ${ }^{1}$, Sang-Hun Lee $^{2}$ and Dong-Suk Yang ${ }^{3}$ \\ (Received March 5, 2011 / Revised April 5, 2011 / Accepted April 20, 2011)
}

\begin{abstract}
Recently, the construction of U-City or of U-City service (U-service) in many kinds of urban development projects becomes the general trend. However, as the construction of U-city comes into the spotlight like the trend of the times, various service constructions are being indiscreetly implemented since it's processed focusing on local specialized projects or local landmark project by a local autonomous entity or an institute in charge being off the original purpose of the improvement of living quality of residents and the efficiency of urban management, which causes a number of problems on the process, maintenance, operation and management of those projects.

Therefore, this study is to derive the standard pattern of U-service construction through the analysis of patterns and numbers of U-service and problems during the process of construction in domestic U-City construction case district, and is aimed to suggest the reasonable direction of service construction based on this. 11 projects areas in which data related to U-service are available among U-City construction project areas were selected for the subjects of this study, and it's standardized with 228 detailed unit services that were suggested by U-Eco City R\&D and with 11 service domains that are regulated in $\ulcorner$ the Act of ubiquitous city construction etc., , and it is limited to services that were suggested in U-City case area of which design was completed by July, 2010 based on this.

The actual state of various U-service construction is analyzed through case studies as well as reviews on the legal and theoretical concept and the method of pattern classification of U-service, the plan for the standardization (pattern classification) of U-service and the plan for the construction body of service and to share the costs are suggested as the plan to construct reasonable U-service based on this for the method and the procedure of this study

For the method to construct U-service, the plan to classify the pattern of U-service into the basic service and additional service is suggested, and whether it has the publicity, whether urban infrastructure is included, whether utilities are included, the body of realization, the recipients, the urgency, the importance and the spreading, etc. are suggested for the index to determine the pattern of service. The method to get the executor of a project to construct the basic service, the method to get the executor of a project to construct the most basic service among the group classification of service and to get a private entity and a local autonomous entity to perform additional service in the future, and the method to construct the whole service and to distribute the construction costs were suggested, and the first one that determines the body of construction after dividing U-service into the basic service and the additional service was evaluated to be the most reasonable one. And the plan to solve the problem that the excessive construction costs of U-service are shifted onto the executor of a project through benefit principle, balanced distribution principle and consultation and mediation between the interested parties was suggested for the criteria to share the costs.
\end{abstract}

Key words: U-City Service, U-Eco City, Classification of U-Service

\section{Introduction}

\subsection{Background and Purpose}

Recently, the construction of U-City or of U-City Service (hereinafter called U-service) becomes the general trend. U-City means a city that provides many kinds of ubiquitous services such as administration, transportation, health, medical service, welfare etc. for the competitive power and the improvement of living quality of residents anywhere at any time. At this time, $\mathrm{U}$-service that U-City provides is very various, which are variously called by grouping them as u-Home, u-Work, u-Traffic, u-Health, u-Environment, u-Education etc. according to the condition of the corresponding local autonomous entity and a category of the industry.

The construction of U-city through providing such ubiquitous service is on the rise as a plan able to solve urban problems that

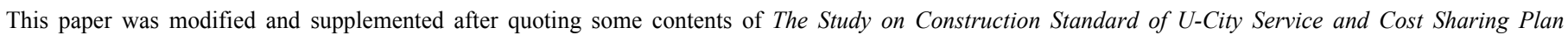
(LHI, 2011).

1) Research Fellow, Land \& Housing Institute (Main author: yjr412@lh.or.kr)

2) Research Fellow, Land \& Housing Institute (Corresponding author: icarus@lh.or.kr)

3) Research Fellow, Land \& Housing Institute 
occur due to overpopulation and scarce resources and rapid economic and social changes with low costs and high efficiency by the cutting-edge technologies. However, as the construction of U-city comes into the spotlight like the trend of the times, a number of service are being indiscreetly constructed without a standard basis since it's processed focusing on projects for local specialized projects or projects of pledges and local public relations by an institute in charge etc. being off the original purpose of the improvement of living quality of residents and the efficiency of urban management. Consequently, U-City implementation projects areas cause many problems on maintenance, operation and management as well as the process of construction projects.

Especially, the excessive service construction is reflected on the construction costs, which leads to the rise of sales price and passes onto the executor of a project as a burden of the project costs, and the problem of the delay of the change-over occurs due to supporting the operation costs for the operation of the constructed service and the demand for additional installation of facilities between a local autonomous entity and the executor of a project.

Therefore, this study is aimed to derive the standard pattern to construct $\mathrm{U}$-service through the analysis of patterns and numbers, and of problems during the process of construction of $\mathrm{U}$-service that is being constructed in domestic U-City construction cases areas and to suggest the direction of reasonable service construction based on this.

\subsection{Method and Scope}

It is desirable to limit the time scope of this study into since $\ulcorner$ The law of construction of ubiquitous city etc.(hereinafter, called as "U-City law")」 that is an institutional basis of U-City was enacted but the time scope of this study was set up from 2008 until a recent date considering a new town in Dong Tan, Hwa Sung (which was completed in September 2008) in which U-City was constructed for the first time.

And 11 projects areas of which data related to U-service are available among U-City construction projects areas were selected for the subjects of this study, and the kinds of U-service that were analyzed in this paper were limited to 11 service domains that are regulated in U-City law and to 228 unit services that were suggested by U-Eco City R\&D results and to services that were suggested in U-City case area of which design was completed as of July, 2010.

\section{Theoretical Review}

\subsection{Concept of U-Service Classification}

U-service can be defined as follows based on the concept of ubiquitous city service of U-City law. That is, U-service means the intelligent urban infrastructure ${ }^{1)}$ through ubiquitous urban technological service and various cutting-edge public service that is derived from urban technology itself. The ubiquitous urban service that is defined in terms of the law is classified according to the view of implementation and the view of recipients (Table 1).

Table 1. U-City Service Followed in Viewpoint2)

\begin{tabular}{|c|c|c|}
\hline \multicolumn{2}{|c|}{ Classification } & Ubiquitous Service \\
\hline \multirow{2}{*}{$\begin{array}{c}\text { View of } \\
\text { Implementation }\end{array}$} & $\begin{array}{l}\text { Government/ } \\
\text { Public } \\
\text { Sector }\end{array}$ & $\begin{array}{l}\text { Information \& Communication Network, } \\
\text { Social/Welfare Infrastructure, Environ- } \\
\text { mental Infrastructure, Roads/Traffic } \\
\text { Infrastructure, Industrial Infrastructure }\end{array}$ \\
\hline & $\begin{array}{l}\text { Private } \\
\text { Sector }\end{array}$ & $\begin{array}{l}\text { Car Industry, Distribution Industry, } \\
\text { Medical Industry, Retail Industry, } \\
\text { Information \& Household Appliances } \\
\text { Industry }\end{array}$ \\
\hline \multirow{3}{*}{$\begin{array}{l}\text { View of } \\
\text { Recipients }\end{array}$} & Private & $\begin{array}{l}\text { U-Home, U-Community, U-Education, } \\
\text { U-Library, U-Museum, U-Fitness, } \\
\text { U-Shopping }\end{array}$ \\
\hline & Enterprise & $\begin{array}{l}\text { U-Building, U-SCM, U-Logistics, } \\
\text { U-Office, U-Convention }\end{array}$ \\
\hline & Government & $\begin{array}{l}\text { U-Government, ITS, U-City, U-Disaster } \\
\text { Prevention, U-National Defense, } \\
\text { U-Disaster Management }\end{array}$ \\
\hline
\end{tabular}

According to the criteria that are defined in the current law, the type of U-service is classified into 11 fields such as administration, transportation, health/medical service/ welfare, environment, security/disaster prevention, maintenance of facilities, education, culture/tourism/sports, distribution, labor/employment, and others.

And it's classified into 78 services by medium classification and 228 unit services according to the results of U-Eco City R\&D that is being promoted as a government-run project (Table 2).

Other than this, the classification of types of U-service is diversely suggested, which can be looked into through the review of the previous studies.

\subsection{Review of Previous Studies on U-Service}

The following representative five studies can be analyzed in terms of the previous studies related to U-service

First, the research by Jung et al. (2009) suggested methodological framework to establish newly standard system of U-service and to derive services. This study suggested the classification standard with multi-dimensional service areas of 9 types, not a simple classification standard such as the existing large/medium/ small classification for the classification standard of services.

The study of Woo-Su, Jung (2007) classified services by areas to select the priorities of promising services of U-City and

1) The urban infrastructure here corresponds to facilities able to realize u-service or 22 facilities for the execution of pilot projects among 53 facilities that are regulated in Article 2 of the Act of Land Planning and use.

2) The Act of Ubiquitous City Construction 
Table 2. Classification Pattern of Current U-Service

\begin{tabular}{|c|c|c|c|}
\hline Law & U-Eco City R\&D & Law & U-Eco City R\&D \\
\hline Administration & Field administration support, $\cdots$ & Maintenance of Facilities & Maintenance service of road facilities, $\cdots$ \\
\hline Transportation & Management service of transportation, $\cdots$ & Education & U-Kindergarten service, $\cdots$ \\
\hline Environment & Pollution control service, $\cdots$ & Culture/Tourism/Sports & Cultural facilities maintenance, $\cdots$ \\
\hline $\begin{array}{c}\text { Security } \\
\text { Disaster Prevention }\end{array}$ & Rescue/First Aid, $\cdots$ & Distribution & Traceability management, $\cdots$ \\
\hline Education & U-Kindergarten service, $\cdots$ & $\begin{array}{c}\text { Labor } \\
\text { Employment }\end{array}$ & Job information service, $\cdots$ \\
\hline Others & Home management service, $\cdots$ & Health/Medical Service/Welfare & Healthcare service, $\cdots$ \\
\hline Remarks & \multicolumn{3}{|c|}{ Legal Classification: 11 cases, U-Eco City R\&D: 78cases } \\
\hline
\end{tabular}

Table 3. U-Service Classification Standards in the Previous Studies \& Their Limit3)

\begin{tabular}{|c|c|c|}
\hline Project & Classification Standard & Limit of Study \\
\hline U-City Realization Strategy(2005) & Infrastructure by Usage/Space & $\begin{array}{l}\text {-Included the basic functions but insufficient consideration on specialized function } \\
\text {-Detailed classification standards not existed }\end{array}$ \\
\hline $\begin{array}{l}\text { Korean-Type U-City Model } \\
\text { Suggestion(2005) }\end{array}$ & Urban Function & $\begin{array}{l}\text {-Simple service groups focusing on urban functions listed } \\
\text {-Insufficient consideration on new service area } \\
\text { - Detailed classification standards not existed }\end{array}$ \\
\hline $\begin{array}{l}\text { Trend of U-City Industry and } \\
\text { Service Classification(2006) }\end{array}$ & $\begin{array}{l}\text { Industry classification based on } \\
\text { private, company and government }\end{array}$ & $\begin{array}{l}\text {-Specialized function service area omitted } \\
\text {-Insufficient segmentation of service area }\end{array}$ \\
\hline $\begin{array}{l}\text { U-City Applied Survive Model } \\
\text { Study(2005) }\end{array}$ & Urban activities, Urban space & $\begin{array}{l}\text {-Insufficient hierarchical structuralization of urban space and activities } \\
\text {-Main agent of service activities omitted }\end{array}$ \\
\hline $\begin{array}{l}\text { The Standardization Plan of U-City } \\
\text { Infrastructure-Technology:Service } \\
\text { Model(2006) }\end{array}$ & $\begin{array}{c}\text { The main agent utilizing services, } \\
\text { Applied job area, Service } \\
\text { activities }\end{array}$ & $\begin{array}{l}\text {-Insufficient consideration on urban basis and specialized function } \\
\text {-Ambiguous classification of functions and roles of basic service and public } \\
\text { service }\end{array}$ \\
\hline
\end{tabular}

according to that, it suggested the classification standard such as industry classification, the main agent that supplies and uses it, the demand and supply of services and so on.

The study from the Ministry of Information \& Communication (2006) classified U-service with large/medium/small classification system that has vertical hierarchy structure of each service by investigating U-service with the subjects of domestic 58 companies. At this time, the large classification was based on 4 standards such as infrastructure service, public sector, business sector and living sector.

Other than this, the study of Hyun-Gon, Kim (2005) classified U-service into common service and specialized service. The common service is to manage the urban infrastructure or related with the safety of citizens, and the specialized service was defined as a service that needs development to be suitable for the function and the purpose of a city.

As such, the previous studies suggesting the classification standard of U-service have a basis of dividing most services into

3) Jeong, Keong-Seok et al(2009), A Study on U-City Service Classification and the Service Framework for the Standardization of U-City Service. two parts such as the public sector and the private sector, and show the limit as shown in Table 3.

Therefore, this paper is aimed to supplement the limit of the previous studies and to improve the classification standard of service through deriving various standards such as the main agent of realization and of benefits to suggest the reasonable direction of U-service construction. Also, presents the classification standard which divides a service with basic/annexed service and the cost-sharing standard, in which there is a differentiation from the previous studies.

\section{Analysis of the State of U-City Service Construction}

\subsection{Overview}

The subject of investigation for the actual state of U-service construction was 11 service construction areas that were processed further than the design development phase among U-City construction projects areas that are defined by ${ }^{\ulcorner}$The law of construction of ubiquitous city etc. $\lrcorner$ and the procedure and methods of investigation and analysis of patterns and the status of construction of U-service are as follows Fig. 1. 
Contents Collection of 119 Services in Total 11 Area

(USP, Basic, Design Development, Internet and Survey)

$$
乃
$$

Definition of Service Name and Function

(Arrangement of Collected Service Names and Service Functions)

\section{ת}

Establishment of Classification Standard of U-Service (Utilization of 11 legal standards and 78 and 227 unit service classification standards that are derived from U-Eco City R\&D)

\section{乃}

\section{Classification of Service
(Mapping of legal standards and U-Eco City R\&D Classification Standards)}

乃

Analysis Cases and Draw a Conclusion(U-City Service Standard of Implement \& Cost Sharing)

Fig. 1. Analysis Procedure of the Actual State of U-Service Construction

Table 4. The Current Status of Case Districts for the Subject of U-Service Analysis

\begin{tabular}{|c|c|c|c|c|c|c|c|}
\hline \multirow[t]{2}{*}{ Case } & \multirow[t]{2}{*}{ Districts } & \multirow{2}{*}{$\begin{array}{c}\text { Area } \\
\left(\text { Thou.m }{ }^{2}\right)\end{array}$} & \multirow{2}{*}{$\begin{array}{c}\text { City } \\
\text { Construction } \\
\text { Cost } \\
\text { (Mil.KRW) }\end{array}$} & \multirow{2}{*}{$\begin{array}{c}\text { U-City } \\
\text { Cost } \\
\text { (Mil.KRW) }\end{array}$} & \multirow[t]{2}{*}{$\begin{array}{l}\text { No. of } \\
\text { Service }\end{array}$} & \multicolumn{2}{|c|}{$\begin{array}{c}\text { U-Service } \\
\text { Construction Cost } \\
(\text { Mil.KRW })\end{array}$} \\
\hline & & & & & & Total & Average \\
\hline \multirow{7}{*}{$\begin{array}{c}\text { Metrop } \\
\text { olitan } \\
\text { Area }\end{array}$} & Dist. A & 3,492 & 13,730 & $6,800,000$ & 8 & 4,178 & 522 \\
\hline & Dist. B & 3,116 & 14,141 & 220,900 & 13 & 5,537 & 426 \\
\hline & Dist. C & 3,024 & 19,163 & $2,166,000$ & 9 & 11,000 & 1,222 \\
\hline & Dist. D & 9,009 & 44,700 & $4,235,300$ & 14 & 16,458 & 1,176 \\
\hline & Dist. E & 9,549 & 103,000 & $8,728,200$ & 33 & 37,179 & 1,126 \\
\hline & Dist. F & 2,139 & 17,864 & $1,305,242$ & 7 & 7,376 & 1,054 \\
\hline & Dist. G & 9,273 & 99,600 & $8,704,300$ & 16 & 30,008 & 1,875 \\
\hline \multirow{3}{*}{$\begin{array}{c}\text { Local } \\
\text { Area }\end{array}$} & Dist. $\mathrm{H}$ & 11,282 & 55,999 & $9,369,800$ & 20 & 22,405 & 1,120 \\
\hline & Dist. I & 7,013 & 9,500 & 565,500 & 4 & 2,753 & 688 \\
\hline & Dist. J & 3,674 & 19,700 & $1,585,500$ & 11 & 9,893 & 899 \\
\hline
\end{tabular}

As a result of analysis according to that, it was found that the average construction cases by each area in 11 districts 4 ) was around $18 \mathrm{U}$-Service, but the deflection in construction costs was shown to be very large due to the different levels of U-service standardization and service construction(Table 4).

4) The concrete names and contents of 11 districts that are the subjects of this study were not described here for information security of the corresponding project districts and a local autonomous entity.

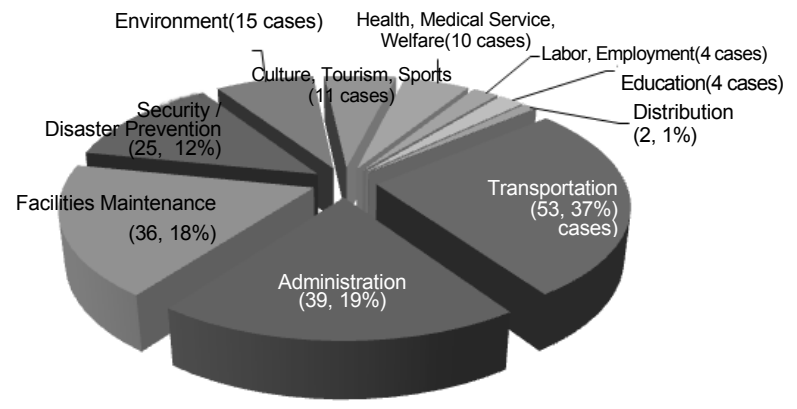

Fig. 2. Current Status of U-Service Construction by Types

\subsection{Current Status of U-City Service Construction}

\section{(1) Current Status of Construction by Service Pattems}

If the surveyed 199 services are classified by 11 patterns of legal classification, the most constructed services were transportation, administration, maintenance of facilities, security/disaster prevention and environment area, and 5 services above take up around $84 \%$ of the total.

(2) Current Status of Service Construction by Project Districts

It was found that the weight of service patterns was diversely constructed by each area as shown in Fig. 3 in terms of the current status of distribution by project districts. For example, while more weight was given to the case of $\mathrm{H}$ district compared to other districts in the area of maintenance of facilities and education, $\mathrm{J}$ district showed very high weight in the education sector. And $\mathrm{K}$ district was found that a wide range of services were constructed across transportation, security/disaster prevention, administration, culture, tourism and sports.

This result may be considered as a phenomenon related with the features of a city or a region and it can be seen as a phenomenon that construct public services(transportation, administration, maintenance of facilities, security/disaster prevention and environment area) commonly from the district most.

According to the analysis result of the actual condition of construction service compared to service construction plans by project districts, the planned 29 services that were scheduled to be constructed were reduced to 4 services, and A district was found that 9 services was reduced to 8 services by each project district compared to the initial plan.

Also the number of U-Service decreased about $27 \%$ degree to compare the service construction present condition of master plan(USP) and execution plan5).

This implies that even though each project district is constructing various services, there is actually a limit in the scope of service construction.

5) From the related document, the number of U-Service was investigated with 18.9 in master plan(USP) and with 13.5 in execution plan. 


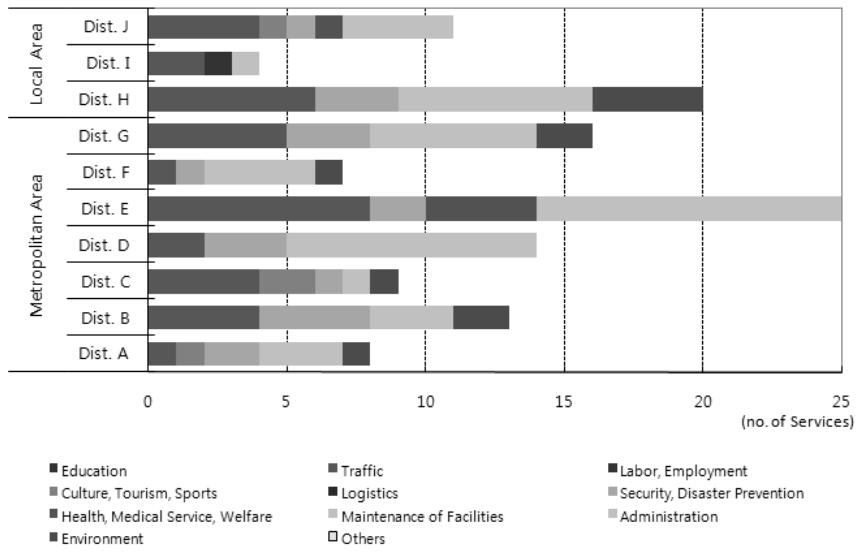

Fig. 3. Status of U-Service Construction by Districts

\section{(3) Weight of Service Construction Cost by Districts and Pattems}

As a result of looking into U-service construction costs $\left.{ }^{6}\right)$ per unit area by project districts, the feature as shown in Fig. 4 was analyzed.

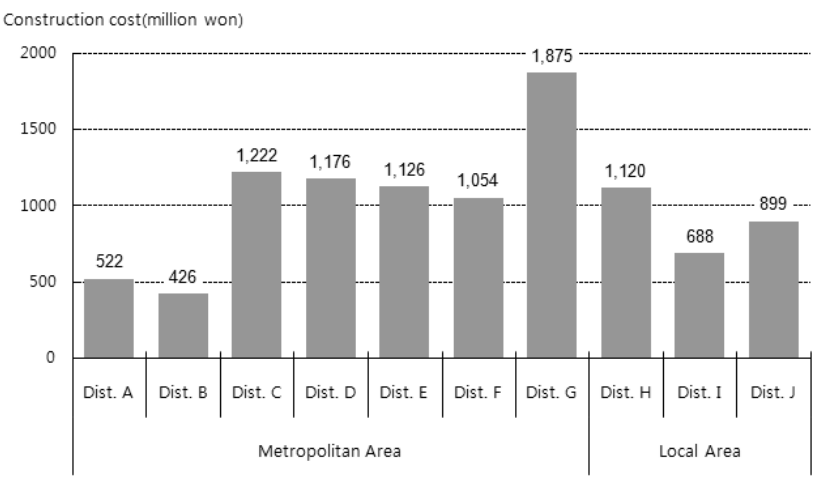

Fig. 4. Weight of U-Service Construction Costs by Districts

That is, while $\mathrm{G}$ district in the Metropolitan area was the highest in the U-City construction costs per unit area followed by C.D.E.F districts in the Metropolitan area and $\mathrm{H}$ district in local area that showed similarity, I.J districts in local area and A.B districts in the Metropolitan area were analyzed to be low, which showed that there was no features by regions in U-service construction.

\subsection{Characteristics of High Rank U-Service}

As a result of analysis of the features of distribution in detail of upper 5 services such as maintenance of facilities, administration, transportation, security/disaster prevention and environment and so on with a unit of integrated service, the following features were deduced.

6) The construction cost of U-service was estimated by dividing the total amount of U-City construction projects by the number of services
First, speaking of traffic service, it's a service to construct intelligent traffic system by integrating the traffic system into the ubiquitous urban technology, and services such as traffic information, management, the safe driving, public transportation information and so on are being constructed.

Among these, it was especially found that the basic traffic information service, the public transportation information and management service and so on were the most preferred ones.

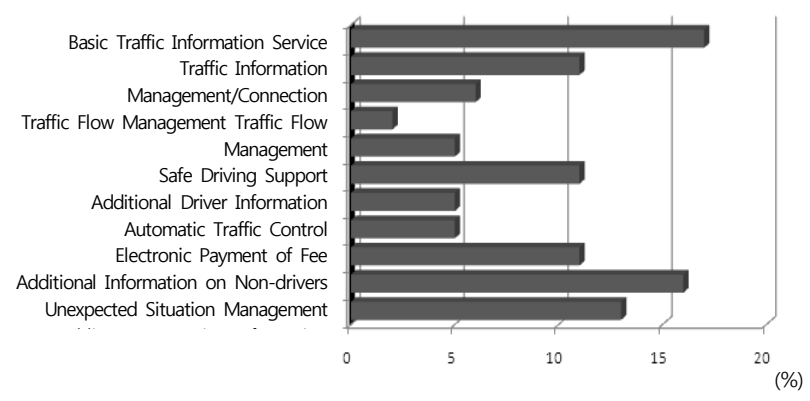

Fig. 5. Composition Ratio graph of Transportation Service

In the case of administrative service, urban integrated portal and local life information portal and so on were the most constructed ones for life convenience, and it was analyzed that much construction is being implemented in the sector of urban landscape management and remote civil affairs administration to manage a line of trees, streetlight and media board and so on.

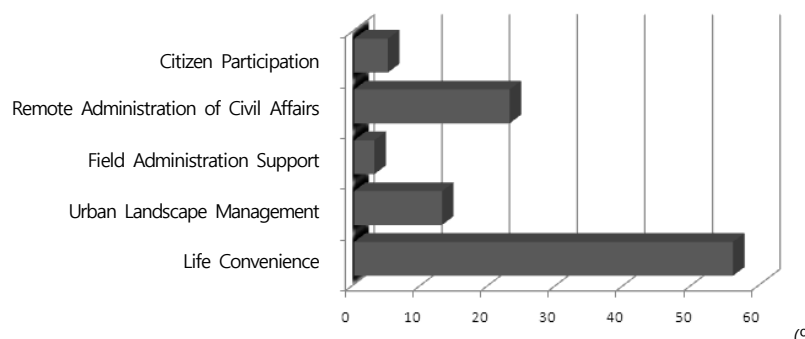

(\%)

Fig. 6. Composition ratio graph of Administrative Service

In the case of maintenance service of facilities, facilities data management and offering service utilizing DB to provide the remote control of facilities and location information, and the management service of underground supplying facilities for the management of utility-pipe conduit, water supply and drainage, and the management service of facilities in a river for a monitoring on facilities in a river were actively being constructed. Besides, the management service of road facilities monitoring the stability of bridges and tunnels and managing the status information of traffic facilities in real time, and the management service of subsidiary facilities and so on to manage public billboards efficiently is being constructed. 


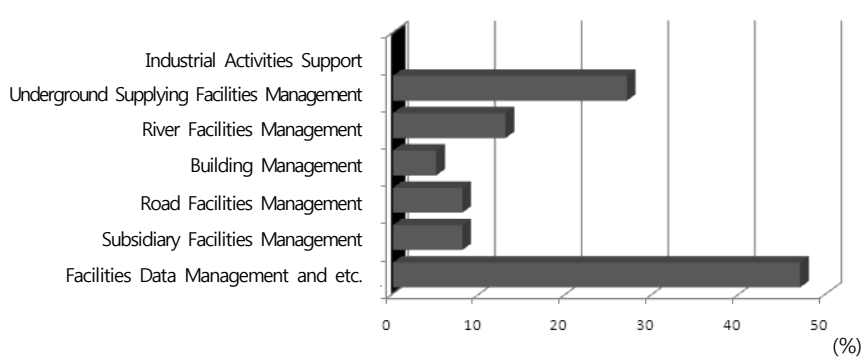

Fig. 7. Composition ratio graph of Facility Management Service

In the case of security/disaster prevention, the public safety, that is, the monitoring service of the safety of public regions or the mobile security information, a criminal's location-tracking, school-zone service and so on are the most actively being constructed ones. In particular, the security service utilizing CCTV is being constructed in all the surveyed area, which can be said that the service is the most necessary and important one. Besides, it was analyzed that the area for personal safety such as the remote checking of each home or fire alarming is also much constructed.

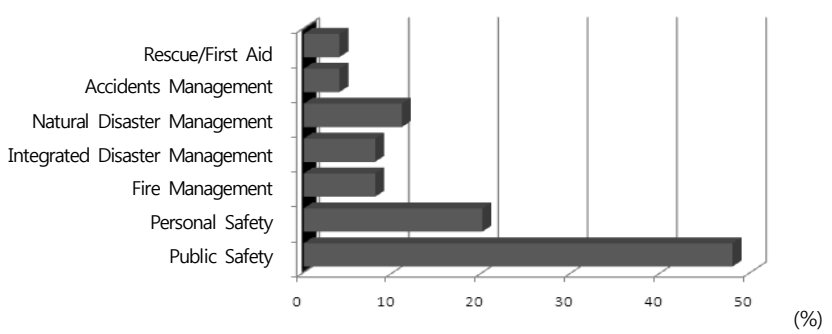

Fig. 8. Composition ratio graph of Security/Disaster Prevention Service

Finally, in the case of environment service, the pollution management service providing residents or a local autonomous entity with convenience by monitoring many kinds of the status of pollution such as water quality, atmosphere etc. in real time was dominantly much being constructed. Besides, the environment-friendly service offering green land/ecological management service was mainly constructed but until now, since there is only alternative water resources management service that efficiently reuses rainwater in terms of the renewable energy, the necessity of construction and utilization of various services preparing for coming energy exhaustion is raised.

\subsection{Summary of Analysis and Deduction of Its Implication}

The deduction of the standard for U-service construction is to judge how to construct $U$-service efficiently with the limited budget to realize the efficient U-City in the end, and based on this, to establish the standard to suggest which method would be desirable for the construction of U-City.

To establish the standard for construction patterns of service, the level of service construction and the standardization of patterns, construction methods and so on must be considered together. However, the standard pattern or the level of U-City service through the analysis of service cases has not yet suggested until now, and any standard for the main agent for the construction is not yet established.

Therefore, for the preceding works for these, this study was intended to standardize the service patterns by analyzing the various classification standards of $\mathrm{U}$-service that the previous studies suggest and the weight and the features by patterns, regions and costs of $\mathrm{U}$-service that is currently being constructed in project districts.

In other words, as a result of matching 199 services that were collected from the case districts with 228 unit services that are the results of U-Eco City R\&D, it was analyzed that 5 services focusing on monitoring the safety of the public regions, the information portal of local life, the basic traffic information, the public transportation information and urban information service based on GIS and so on were constructed in terms of main service patterns.

And through the analysis result of the actual conditions of construction service compared to the construction plan by project districts, it was deduced that the scale of service construction came to be decreased compared to the plan due to the limit of budget for U-service construction. Viewed from the fact that the clear standard is not yet prepared for bearing the costs while the construction cost of $\mathrm{U}$-service is excessive and the fact that many project districts currently planning the construction of U-service also have the target to construct a wide range of service at the stage of USP, it can't guarantee whether the actual construction of service is conducted in the future, and it disproves that it's impossible to construct the efficient U-service.

\section{Improvement Plan for U-City Service Classifi- cation Standard \& Cost Sharing}

\subsection{Classification of U-City Service Patterns and Deduction of Standards}

For the method to improve problems that were deduced from the analysis of the current status and to construct the efficient U-service, it can be considered to classify the patterns of U-service into the basic service and the additional service.

Viewed from the basis of the result of the study up to now, 5 patterns (the upper 5 services such as administration, transportation, security/disaster prevention, environment, etc.) form a large majority in U-service that is being constructed in a majority of project districts. These services correspond to services called urban infrastructure and are the basic services that must be commonly constructed regardless of regional features. Therefore, this study defines the concept of U-service by dividing it into the basic service and the additional service, and is intended to suggest 
Table 5. Classification Standards of Basic Services and Additional Services

\begin{tabular}{c|l|l}
\hline Classification & \multicolumn{1}{|c}{ Basic Services } & \multicolumn{1}{c}{ Additional Services } \\
\hline Definition & $\begin{array}{l}\text {-Services with the purpose of public benefits } \\
\text { Services considered to be able to be reflected on the construction } \\
\text { cost }\end{array}$ & $\begin{array}{l}\text {-Services that need proper development for functions and aims of } \\
\text { each city } \\
\text { Creation of profits, services on which the recipients of services } \\
\text { are added by specific individual/a group/an institute }\end{array}$ \\
\hline Characteristics & -Difficult to make direct profits from the recipients of services & $\begin{array}{l}\text {-Possible to create direct profits } \\
\text {-Possible to organize various consortium in the private sector }\end{array}$ \\
\hline
\end{tabular}

Table 6. Classification Index of U-Service Patterns ${ }^{8)}$

\begin{tabular}{|c|c|c|}
\hline \multicolumn{2}{|c|}{ Service Classification } & Judgement \\
\hline \multirow{4}{*}{$\begin{array}{c}\text { Classification } \\
\text { index }\end{array}$} & Publicity & $\begin{array}{l}\text { To judge whether the service to provide has a feature that it has to be equally provided to a society or many } \\
\text { people and whether it is a case that the public institute such as the government or a local autonomous entity etc. } \\
\text { has to play an role }\end{array}$ \\
\hline & $\begin{array}{l}\text { Inclusion of urban } \\
\text { infrastructure }\end{array}$ & To judge whether the physical part of the service to provide is included in the urban infrastructure \\
\hline & $\begin{array}{l}\text { Inclusion of Major } \\
\text { Facilities \& Major } \\
\text { Agent of Realization }\end{array}$ & $\begin{array}{l}\text { To judge whether the physical part of the service to provide is included in the major facilities or the service is } \\
\text { provided by utilizing the major facilities and to judge with the basis of the major agent of realization }\end{array}$ \\
\hline & Recipient of Benefits & To judge according to users of the service to provide and products which result from it or those who gain profits \\
\hline \multirow{3}{*}{$\begin{array}{l}\text { Priority } \\
\text { index }\end{array}$} & Urgency of Service & $\begin{array}{l}\text { In the case that it is necessary to urgently construct socially, economically and culturally the service to provide, } \\
\text { it is judged to be in high level enough to be included in the essential service compared to other services. }\end{array}$ \\
\hline & Importance of Service & $\begin{array}{l}\text { When considering the current technological skills or all the conditions of the service to provide, in the case of } \\
\text { being acknowledged to have high level of utilization, the priority for construction is judged to be high. }\end{array}$ \\
\hline & Spreading of Service & $\begin{array}{l}\text { When the service to provide is constructed considering the technical skills or all the conditions, in the case that } \\
\text { it has the high level of utilization and the ripple effect of the service, it is judged to have the utmost priority } \\
\text { to be included in the essential service. }\end{array}$ \\
\hline
\end{tabular}

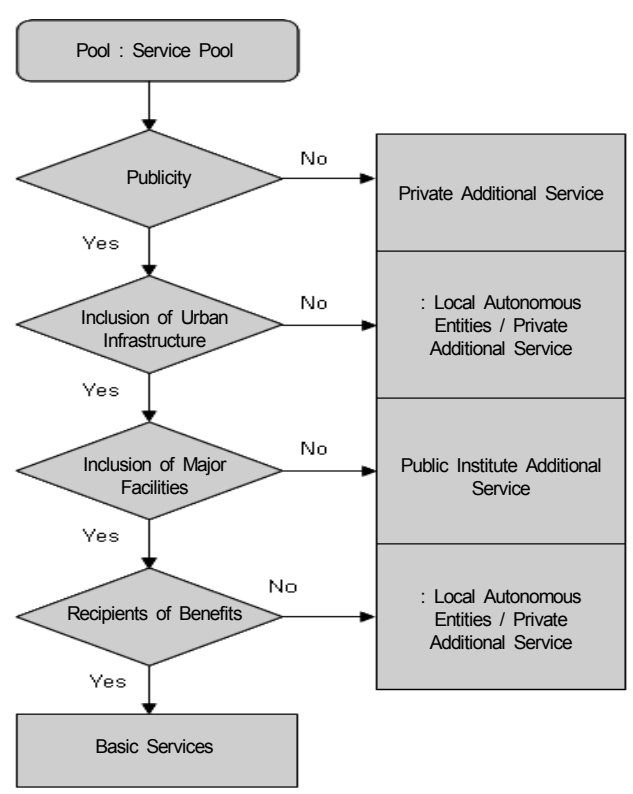

Fig. 9. Procedure of Judgement by the Classification Index of Patters

the index for the classification of the kinds and patterns of individual service and the construction plan.
In other words, a basic service means one with a purpose of public benefits and essential one necessary for the construction of U-City. And the other services are classified as additional services, and those need the development to be proper for functions and aims of each city and it means services that the recipients of those services are added by specific individual/a group/an institute with the created profits.

Of course, since the scale of construction costs of U-service may be largely changed depending on the view of classification and the level of services and items that are difficult to be classified depending on the situations, it's important to prepare for the principle for selecting the basic items. ${ }^{7)}$

Therefore, it is necessary for the classification of service patterns to set up the reasonable index such as the publicity, inclusion of urban infrastructure, inclusion of major facilities, the recipients, the urgency, the importance, the spreading effect and so on, and based on those, the plan to select the service pattern is needed.

7) LH (2009), The Analytical Study on the Economic Feasibility of Construction Projects of U-City and the Level of Financial Contribution of Local Autonomous Entities.

8) Proposes the method that makes 3 priority indexes to set the priority of U-service and makes 4 classification index to set the the 


\subsection{The Construction Plan of U-City Service}

A great deal of construction costs are required to provide various U-services such as convenience and the safety of residents as well as the efficient urban management. It's not proper to aggregate the burden of the executor of a project or residents by fixing excessive construction costs and including them in the construction cost for constructing indiscreet U-services.

Therefore, it is required to prepare for the standard on the main agent for construction and apportionment of costs to construct U-services efficiently.

First of all, the following three methods can be considered for the plan to select the main agent of construction.

First, it's a method to get the executor of a project to construct the basic services, and in the case of additional services, it's possible for additional development even at the stage of construction and operation by sharing the costs with local autonomous entities.

Second, it's a method to get the executor of a project to construct the most basic services among group classification of services and to get the private business and local autonomous entities to conduct the additional services in the future. In other words, the executor of a project makes the standard service model and constructs it focusing on the most basic model, and local autonomous entities construct additional services by introducing some equipment and softwares in the future. Third, it's a method to construct the whole service and to allocate the construction costs and the executor of a project shares a certain rate of the total construction costs after standardizing the average project cost of U-City.

The second one among these three methods is one that is possible only when the standardization of services has to be established to some degree, and in the third one as well, it's impossible to extract the reasonable allocation rate of the construction project cost since the actual constructed sampling project districts are very few.

Therefore, it is judged that the plan to determine the main agent of construction after dividing U-service into the basic service and the additional service which was the first method would be the most reasonable plan. But, in terms of selecting the individual main agent of investment on services, since the scale of construction costs may largely vary depending on cases classification of services and the service level, design methods and the application method and so on, it would be necessary to establish the standard model for U-service and to apply it in the future.

And, for the standard of the cost allocation, it could be considered with the basis of the following principles.

First, it's desirable to apply beneficiary pays principle that

classification of Basic U-Service from this research(through the survey with Experts, Local Self-Government employee, practical person in charge of U-City) those who basically get benefits or use the service to the supply of U-service. In the case of U-service, it must not be overlooked that the benefits of it are given to administration and urban management down to public officials of a local autonomous entity and the central government officials as well as residents in the corresponding region.

Second, the balanced allocation of costs must be executed. It is the government that acquires the most development profits resulting from U-service construction. The central government collects a development share (50\%) etc. and value added tax in the process of many kinds of shares and trades, and the local government collects not only an acquisition tax but also contributed acceptance of many kinds of facilities inside and outside the development area. And it comes to secure the tax resources of local tax such as property tax, urban planning tax, the integrated land tax and so on in the long term. Besides, since there is a finding9) that the construction of U-City affects the rise of price of apartment houses, it would be desirable to allocate the costs properly to local autonomous entities and the central government.

Third, it is necessary to make a reasonable adjustment through consultation between the interested parties(the executor of a project - local autonomous entities) to revitalize the construction of U-service. The reason is that the imputation of costs to the executor of a project may have direct and indirect influences on it such as the relinquishment of a project or the rise of construction costs and so on. Therefore it is necessary to consider the regulation that the executor of a project constructs it within a certain amount compared to the total construction costs and the plan that the exceeding amount is deducted or subtracted from the development shares ${ }^{10}$ ) that the executor of a project paid, or is financially supported within the scope of the reverted part into a local autonomous entity among the development shares paid.

\section{Conclusion}

In this study, the actual conditions of various U-service was analyzed through case studies including the review of legal theoretical concepts of $U$-service and the method of pattern

9) Won, Ji-Young, et al. (2010), “The Analysis of Effect of Ubiquitous Urban Service on the Price of Apartment Houses", Journal of Korean Land.Urban Planning Study, 45(2), April 2010.

10) $50 \%$ of developmental profits is imposed to the executor of a project as the development charge and in the projects that a country or local autonomous entities implement with a purpose for the public, the development charge is completely exempted, and for some projects carried out by the public institute such as local autonomous entities, $\mathrm{LH}$, and local public corporation and so on, $50 \%$ of the development charge is exempted and $50 \%$ of the development charge paid is reverted to a local autonomous entity that the land creating the development profits belongs to and the others are reverted to the country. 
classification. As a result, there are some cases to construct or plan various U-service in the construction project districts of U-City but it could be found that most cases ar partial to 5 services that were previously analyzed.

Besides, in the case to construct various U-service as well, it was found that a problem that it was difficult to construct service due to the reduced number of services or the increase of the executor's burden occurred by the problem such as the allocation of costs unlikely to the plan.

This was fundamentally caused by the facts that the standard pattern for the construction of U-service has not yet established and the standard for U-service such as the main agent of construction and the allocation of costs etc. has not yet been prepared.

Therefore, this study devised a plan of the standardization (classification of patterns) of U-service as a plan for reasonable U-service construction as well as a solution to these problems and suggested a plan for classification standard of service patterns and the main agent of service construction and the allocation of costs

However, this study has a limit in clearly analyzing the features by regions as the subjects of the study were limited to 11 areas because of the limit of data collection and there was no other choice but to use a method to estimate for the collection and the analysis of cost-related data such as construction costs by U-service patterns. Consequently, it is considered that more concrete and deepening analysis would be necessary by supplementing these limits in the succeeding studies.

\section{References}

1. Jung, Keong-Seok et al. (2009), "A Study on U-City Service Classification and the Service Framework for the Standardization of U-City Service", Journal of Korea Planners Association, 44(3): 231 246.

2. Jung, Woo-Su et al. (2007), "A Study on Priorities of u-City Services Using Weighted Model”, Journal of KRIHS, 52: 193 214.

3. Han, In-Gyo et al. (2010), Report of Detailed 1st Stage of the Core 2 of U-Space Construction Technology, U-Eco City Agency, 208 211.

4. Kang, Min-Gu (2007), A Study on the Types of Ubiquitous Public Service that Can be Introduced to the Public Sector : Focused on Chungju City public officials' recognition, Business Adminstration·Public Administration·Foreign Language Graduate School in Chungju National University.

5. Kim, Hyun-Gon (2005), The Status of Ubiquitous Service Use and Survey of Demand : National Life Sector, National Information Society Agency.

6. Kim, Sang-Jun (2006), "The Consideration of a Plan to Utilize U-technology:Service for the Weak", Korea Agency for Digital Opportunity \& Promotion, 3(8): 3 14.

7. National Information Society Agency(2007), Legal Issues Related to Implementation of $u$-Service.

8. Kim, Hyung-Chan et al. (1999), The Study of a Plan to Establish the System of Costs Allocation for Universal Service, Korea Information Strategy Development Institute, 1 118.

9. Lee, Heon-Seok et al. (2000), Determination of market share between railroad and road on the cost minimization base, The Korean Society for Railway, 9(6): 68 76.

10. Choi, Yun-Kil et al. (2009), Derivation of u-City Promotion Direction through an Analysis on Domestic and Foreign of $u$-Service Cases, Korea Institute of Construction Engineering and Management, 255 259.

11. National Information Society Agency (2006), Study on Standardization Strategies for u-City Infrastructure, Technology and Service Model. 